American Journal of Environmental Sciences 7 (6): 542-546, 2011

ISSN 1553-345X

(C) 2011 Science Publications

\title{
Fabrication and Experimental Investigation of PCM Capsules Integrated in Solar Air Heater
}

\author{
${ }^{1,2}$ Mahmud M. Alkilani, ${ }^{1}$ Kamaruzzaman Sopian and ${ }^{1}$ Sohif Mat \\ ${ }^{1}$ Institute of Solar Energy Research, \\ ${ }^{2}$ Faculty of Engineering, \\ University Kebangsaan Malaysia, Selangor Darul Ehsan, Malaysia
}

\begin{abstract}
Problem statement: Thermal Energy Storage (TES) process can reduce the time or rate mismatch between energy supply and energy demand. Organic latent heat materials are suitable to use as storage medium, however, the low thermal conductivity of these materials slow the thermal response during charging and discharging processes. Approach: A solar air heater integrated with (PCM) has been designed, fabricated and tested indoor. The system consists of top glazed isolated duct, air pump and array of PCM capsules plays to absorb the radiation and storing the thermal energy to discharge to demand when no radiation. Two cases were tested for storage medium used pure paraffin wax and paraffin wax-aluminum composite, the aluminum mass fraction was $0.5 \%$ and powder particulate size was $70 \mu \mathrm{m}$. Most of these experiments focused on discharge process. The outlet air temperature and thermal storage efficiency of the system has been studied. Results: Experimental results indicated that the charging time was reduced by approximately $70 \%$ when used the paraffin wax-aluminum composite. The thermal storage efficiency reached the maximum magnitudes 71.9 and $77.18 \%$ at mass flow rates 0.05 and $0.07 \mathrm{~kg} \mathrm{sec}^{-1}$ for pure paraffin wax and the compound respectively. Conclusion: The discharging time was reduced by adding aluminum powder in the wax. The storage efficiency was increased after adding aluminum powder. The encapsulation procedure in this work was also explained.
\end{abstract}

Key words: Air heater, PCM, encapsulation, outlet temperature, discharge process

\section{INTRODUCTION}

Thermal energy storage becomes more important where the energy source intermittent such as solar. Energy storage process can reduce the interrupts in thermal energy supply to the demand. The thermal energy storage can be used in places where there is a variation in solar energy may by clouds like tropical areas or in areas where there is a high difference of temperature between day and night like desert areas.

In field of solar heating systems, water is still used as a heat storage material in liquid based systems, while a rock bed is used for air based system, but when you compare the volume requirements for the storage of heat energy between water and phase change material like Glauber's salt, you will see that the water heat storage requires almost five times amount of space as the Glauber's salt heat storage, this space savings would result in reduced costs for insulation and construction. Alkilani et al. (2009) and Solomon (1981), predicted the behavior of an array of PCM cylinders as a storage unit under some assumptions. The PCM used was a mix of sodium sulfate decahydrate and other salts with melting point of about $12.8^{\circ} \mathrm{C}$, the results obtained from experiments agree fairly well with the predicted results.

Fatah (1995), developed a small and simple solar air heater integrated with thermal energy storage system. A set of copper tubes were filled with Different sensible and latent heat storage materials to study the difference between the materials in performance. Each capsule closed permanently using weld material then welded all the capsules in one row placed at the middle of the collector as an absorber. The results indicated that the heater filled with PCMs with 51 and $43^{\circ} \mathrm{C}$ melting temperatures gives the best performance, otherwise the system daily average efficiency varies between 27 and $63 \%$ depending on the PCM melting temperature, solar intensity and system air flow resistance.

Enibe (2002; 2003), constructed and studied a natural convection solar air heater with phase change

Corresponding Author: Mahmud M. Alkilani, Institute of Solar Energy Research, University Kebangsaan Malaysia, Selangor Darul Ehsan, Malaysia 
Am. J. Environ. Sci., 7 (6): 542-546, 2011

material energy storage used the paraffin wax as a PCM, under natural environmental conditions involving ambient temperature variations in the range $19-41^{\circ} \mathrm{C}$ and daily global irradiation in the range 4.9-19.96 MJ $\mathrm{m}^{-2}$. Peak temperature rise of the heated air was about $15^{\circ} \mathrm{K}$, while peak cumulative useful efficiency was about $50 \%$, the maximum predicted airflow rate was $0.01 \mathrm{~kg} \mathrm{sec}^{-1}$.

In this study, a solar air heater integrated with PCM unit has been designed and fabricated. Its outlet temperature and thermal storage efficiency during discharge process were studied experimentally. The experiments were carried out in indoor condition and parameters were measured by varying the mass flow rate of air.

\section{MATERIALS AND METHODS}

Experimental setup: This system consists of two essential parts which are: a single glazed thermal air collector and PCM storage unit, integrated together in one product. The physical dimensions of the tested thermal air collector are given in Table 1. The design takes into consideration many concerns such as, the integration with PCM storage unit, the simplicity of construction, dismantlement and handling the PCM unit, most of the collector dimensions were proposed in accordance with Choudhury (1995) studies on the design of solar air collectors. The dimensions were $300 \times 128 \times 15 \mathrm{~cm}$ (length $\times$ width $\times$ height), effective glazing area is $217 \times 120 \mathrm{~cm}$ (length $\times$ width). Paraffin wax used as a PCM encapsulated in 53 aluminum cylindrical capsules fabricated in our laboratories. The insulation is glass wool $2.5 \mathrm{~cm}$ thickness. The aluminum capsules were coated with non-selective black paint then placed in the middle of collector arranged inline single row in the cross flow of pumped air as shown in Fig. 1. Spaces opened between the capsules to increase the heat exchanging to the pumped air.

Solar simulator: Thermal air collector integrated with PCM unit was tested under solar simulator which has 40 tungsten halogen lamps each has $500 \mathrm{~W}$ and rated at $240 \mathrm{~V}$ and $11 \mathrm{~A}$. The halogen lamps are arranged in 8 lines where each line contains 4 or 5 lamps for uniform distribution of irradiance. The dimensions of the simulator are $320 \times 210 \mathrm{~cm}$. the distance chosen is suitable with an average distance between the simulator lamps built by (Garg et al., 1985) for $35 \mathrm{~cm}$. The distance between simulator and the collector surface is $120 \mathrm{~cm}$. Intensity of the radiation simulator is controlled by 40 controllers.

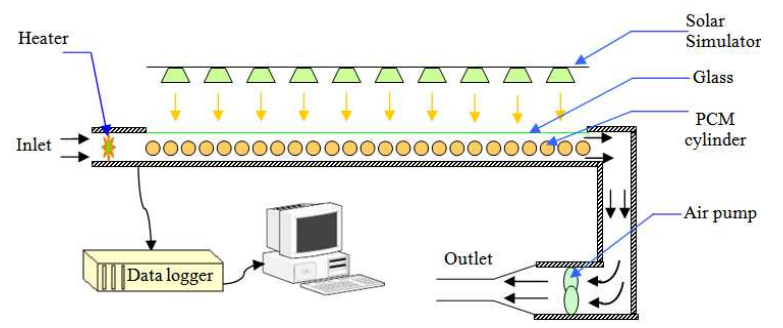

Fig. 1: Schematic diagram of the experimental system

Table 1: Thermo physical dimensions of the tested thermal air collector

\begin{tabular}{ll}
\hline Parameter & Value \\
\hline Collector length & $300 \mathrm{~cm}$ \\
Collector width & $128 \mathrm{~cm}$ \\
Collector height & $15 \mathrm{~cm}$ \\
Channel depth & $10 \mathrm{~cm}$ \\
Effective glazing area & $217 \times 120 \mathrm{~cm}$ \\
Glass thickness & $0.4 \mathrm{~cm}$ \\
Insulation thickness (glass wool) & $2.5 \mathrm{~cm}$ \\
Spacing between capsules & $0.2 \mathrm{~cm}$ \\
Capsule surface emmittance & 0.98 \\
Capsule surface absorbance & 0.98 \\
\hline
\end{tabular}

Table 2: Thermophysical properties of paraffin wax phase change material

\begin{tabular}{ll}
\hline Property & Value \\
\hline Latent heat of fusion & $189 \mathrm{~kJ} / \mathrm{kg}$ \\
Melting temperature & $53^{\circ} \mathrm{C}$ \\
Thermal conductivity & $0.2 \mathrm{~W} / \mathrm{m}^{\circ} \mathrm{K}$ \\
Specific heat & $2.5 \mathrm{~kJ} / \mathrm{kg}^{\circ} \mathrm{K}$ \\
Liquid density & $770 \mathrm{~kg} \mathrm{~m}^{-3}$ \\
Kinematic viscosity & $3.3-3.6 \mathrm{~mm}^{2} / \mathrm{sec}$ at $373^{\circ} \mathrm{K}$ \\
\hline
\end{tabular}

Fabrication of capsules: Microencapsulation means filling the PCM in a macroscopic containment that fit amounts from several $\mathrm{ml}$ up to several liters. These are often containers and bags made of metal or plastic (Mehling and Cabeza, 2008). The advantage of the microencapsulation is that the possibility to apply with both liquid and air as heat transfer fluids and easier to ship and handle (Lane, 1976; 1980; Baehr and Stephan, 2010).

In general, the storage unit should satisfy the following specifications: less volume, higher thermal storage efficiency, easier for installation (Dismantling and handling), cheaper, storage medium non hazardous and non interactive with the container. The thermophysical properties of the PCM are given in Table 2. While the physical dimensions of the capsules are given in Table 3. The storage unit consists of $53 \mathrm{~kg}$ paraffin wax encapsulated in a set of $3.77 \mathrm{~cm}$ diameter aluminum tubes. These capsules are work as a solar energy absorber and to store the thermal energy. 


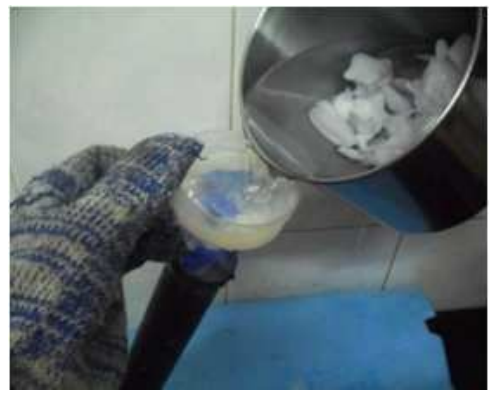

(a)

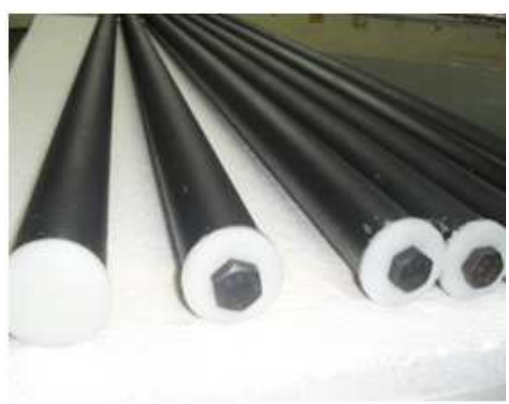

(b)

Fig. 2: Encapsulation process: (a) melting and pouring the paraffin wax (b) sealing the capsules

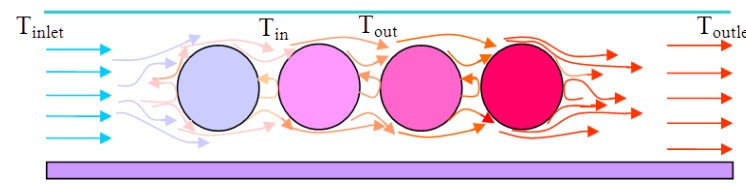

Fig. 3: Schematic diagram of freezing process in row of PCM cylinders in cross flow of pumped air

Table 3: Capsules physical dimensions

\begin{tabular}{ll}
\hline Parameter & Value \\
\hline Number of capsules & 53 \\
Capsule length & $120 \mathrm{~cm}$ \\
Capsule outer diameter & $3.770 \mathrm{~cm}$ \\
Capsule thickness & $0.15 \mathrm{~cm}$ \\
Total weight of PCM & $50 \mathrm{~kg}$ \\
\hline
\end{tabular}

The capsule ends were sealed by nylon caps fixed by screws and epoxy has properties, waterproof, resistant to chemical and heat, available in the market, it commercial name is Araldite. The paraffin blocks were shredded into small pieces for easy melting then poured inside the tube via a big screwed hole made in order to re-use the capsule many times, such as if need to add some additives to enhance heat transfer or change the entire storage medium as shown in Fig. 2. The screw was closed when the tube was filled with paraffin wax in liquid phase, so as to reduce the PCM pressure during charging process. All these precautions were taken to prevent any leakage or expansion problems. The PCM melting point was tested experimentally in our laboratory using electro thermal melting point apparatus model 9100 refers that the melting point between $53-54^{\circ} \mathrm{C}$.

Theoretical Background: During discharge process when no radiation and the PCM was initially at liquid phase. We consider a typical PCM cylinder in a row of $\mathrm{N}$ PCM cylinders in cross flow of pumped air has a constant inlet temperature $\mathrm{T}_{\mathrm{i}}$ and a constant mass flow rate of $\dot{\mathrm{m}}_{\mathrm{a}}$, let $\mathrm{T}_{\mathrm{in}}, \mathrm{T}_{\text {out }}$ be the transfer fluid temperature before reaching a typical cylinder and after leaving it as shown in Fig. 3, conservation of energy Eq. 1 will be:

$$
\left(\mathrm{T}_{\text {in }}-\mathrm{T}_{\text {out }}\right) \mathrm{C}_{\mathrm{a}} \dot{\mathrm{m}}_{\mathrm{a}}=2 \pi \mathrm{R} \mathrm{olh}\left(\mathrm{T}_{\text {in }}-\mathrm{T}_{\text {sfc }}\right)+\varepsilon A \sigma\left(\mathrm{T}_{\text {sfc }}^{4}-\mathrm{T}_{\text {sur }}^{4}\right)
$$

Where:

$\mathrm{T}_{\mathrm{in}}=$ Air temperature before the cylinder $\left({ }^{\circ} \mathrm{C}\right)$

$\mathrm{T}_{\text {out }}=$ Air temperature before the cylinder $\left({ }^{\circ} \mathrm{C}\right)$

$\mathrm{C}_{\mathrm{a}}=$ Specific heat for air $\left(\mathrm{kJ} / \mathrm{kg}{ }^{\circ} \mathrm{C}\right)$

$\dot{\mathrm{m}}=$ Mass flow rate $(\mathrm{kg} / \mathrm{s})$

$\mathrm{R}_{\mathrm{o}}=$ Outside radius $(\mathrm{m})$

$1=$ Capsule length $(\mathrm{m})$

$\mathrm{h}=$ Heat transfer coefficient $\left(\mathrm{kJ} / \mathrm{m}^{2} \mathrm{~s}^{\circ} \mathrm{C}\right)$

$\mathrm{T}_{\text {sfc }}=$ Capsule surface temperature $\left({ }^{\circ} \mathrm{C}\right)$

$\varepsilon \quad=$ Emissivity (-)

A $=$ Capsule area $\left(\mathrm{m}^{2}\right)$

$\sigma=$ Stephan-Boltzman constant $\left(\mathrm{kW} / \mathrm{m}^{2} \mathrm{~K}^{4}\right)$

$\mathrm{T}_{\text {sur }}=$ Surrounding temperature $\left({ }^{\circ} \mathrm{C}\right)$

$\mathrm{T}_{\mathrm{m}}=$ Melting temperature $\left({ }^{\circ} \mathrm{C}\right)$

The heat transfer coefficient of flow normal to banks of tubes in line approximated (McAdams, 1954):

$\mathrm{h}=\left(\mathrm{K}_{\mathrm{a}} / \mathrm{D}_{\mathrm{o}}\right) \mathrm{b}_{2} \operatorname{Re}^{\mathrm{n}}$

Where:

$\mathrm{K}_{\mathrm{a}} \quad=$ Thermal conductivity of air $\left(\mathrm{kW} / \mathrm{m}{ }^{\circ} \mathrm{C}\right)$

$\mathrm{D}_{\mathrm{o}} \quad=$ Outside diameter $(\mathrm{m})$

$\operatorname{Re} \quad=$ Reynolds number $(-)$

$\mathrm{b}_{2}$ and $\mathrm{n}=$ Constants equal to 0.3 and 0.6 respectively

Equation 2 used by (Solomon, 1981) to predict the behavior of a PCM cylinder array.

The cost of materials and fabrication of the TES unit and its efficiency are related to each other. The efficiency of thermal energy storage systems can be defined as the ratio of the energy extracted from the thermal storage unit to the energy stored into it. The following Eq. 3 has been used to compute the efficiency of thermal energy storage: 
Am. J. Environ. Sci., 7 (6): 542-546, 2011

$\eta=Q_{0} / Q_{o}+Q_{L}$

Where:

$\eta=$ TES efficiency
$\mathrm{Q}_{\mathrm{o}}=$ Heat retrievable from TES $(\mathrm{kw})$
$\mathrm{Q}_{\mathrm{L}}=$ Heat lost to the environment $(\mathrm{kw})$

\section{RESULTS AND DISCUSSION}

The experiments were carried out on this system during charge and discharge period to evaluate the outlet air temperature and to monitor the PCM temperature. The PCM unit has been charged using solar simulator by $700 \mathrm{~W} \mathrm{~m}^{-2}$ and inlet temperature was $35^{\circ} \mathrm{C}$. The air temperature increased from $35^{\circ} \mathrm{C}$ and reached $51{ }^{\circ} \mathrm{C}$ at the last capsule during discharge process when the mass flow rate at a constant value equal to $0.05 \mathrm{~kg} \mathrm{sec}^{-1}$.

Figure 4 indicates that for thermocouple fixed in the middle of a capsule, at the melting temperature $\left(\mathrm{T}_{\mathrm{m}}\right)$ the melting time for pure wax was $70 \mathrm{~min}$, while that for the composite was approximately $50 \mathrm{~min}$, when the air mass flow rate and initial temperature of PCM were $0.05 \mathrm{~kg} \mathrm{sec}^{-1}$ and $32^{\circ} \mathrm{C}$ respectively. The increase in the temperature of the composite is due to the high thermal conductivity of the aluminum powder. Variation of outlet temperature of air heater versus time during discharge process when used pure PCM is shown in Fig. 5, where mass flow rate was varied from 0.03-0.09 $\mathrm{kg} \mathrm{sec}$. The stability for outlet air temperature is clarified in the curves during time intervals of around 45-50 min. The effect on PCM temperature by varying the mass flow rate during discharge process is shown in Fig. 6 when $T_{i}=35^{\circ} \mathrm{C}$. Mass flow rate varies from 0.03 , $0.05,0.07$ and $0.09 \mathrm{~kg} \mathrm{sec}^{-1}$. Figure 7 shows that the Variations of compound temperature versus time (the mass fraction was $0.5 \mathrm{Al}$ powder) at various mass flow rate and $\mathrm{T}_{\mathrm{i}}=35^{\circ} \mathrm{C}$. Comparison of temperature inside the PCM for both cases of pure paraffin and composite (discharge process) shown in Fig. 8 at $\dot{\mathrm{m}}=0.03 \mathrm{~kg}$ $\sec ^{-1}$ and $T_{i}=35^{\circ} \mathrm{C}$. From the figure, we can see that the heat transfer rate is increased for composite as compared to that for paraffin wax.

In Fig. 9 as the mass flow rate increases, thermal storage efficiency increases and approaches the stability condition in the flow rate over $0.05 \mathrm{~kg} \mathrm{sec}{ }^{-1}$. The maximum value of the storage efficiency is equal to $71.13 \%$ for pure paraffin wax at mass flow rate while reaches $76.85 \%$ for the composite. The melting and freezing time decreases with increase in mass flow rate, also decreases when the aluminum powder percentage in the compound increased.

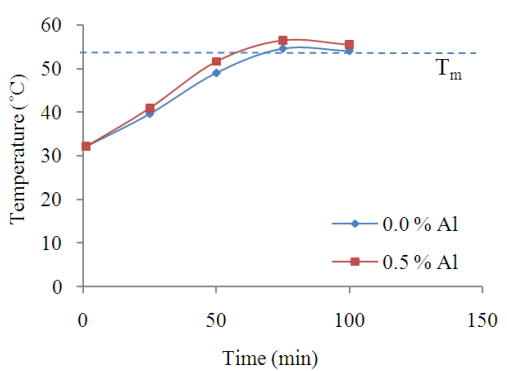

Fig. 4: Variation of PCM temperature inside the capsule for pure paraffin wax and composite (charging process)

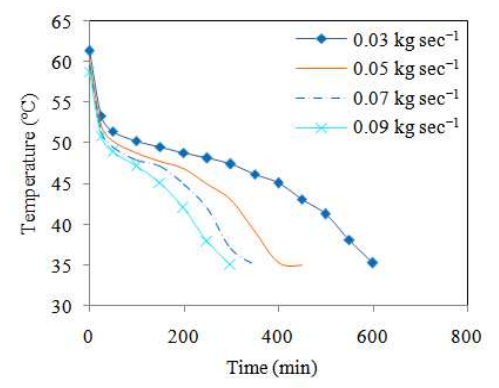

Fig. 5: Experimental variation of outlet temperature for pure wax at various mass flow rates and $T_{i}=$ $35^{\circ} \mathrm{C}$

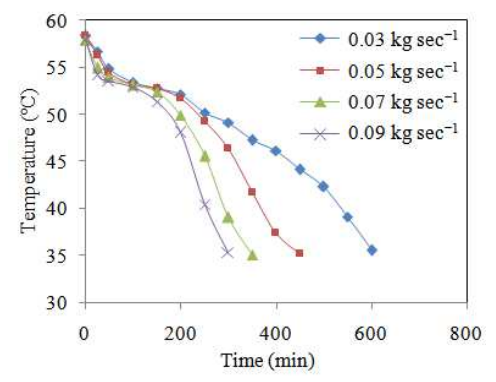

Fig. 6: Variations of pure PCM temperature versus time at various mass flow rates (discharging process)

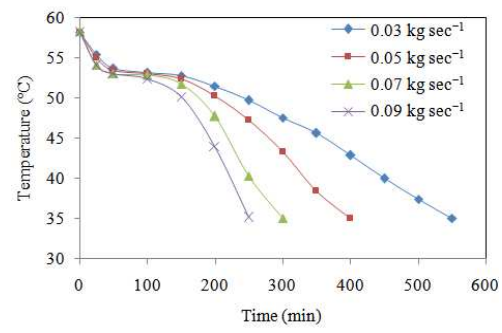

Fig. 7: Variations of compound temperature versus time at various mass flow rate and $\mathrm{T}_{\mathrm{i}}=35^{\circ} \mathrm{C}$ 
Am. J. Environ. Sci., 7 (6): 542-546, 2011

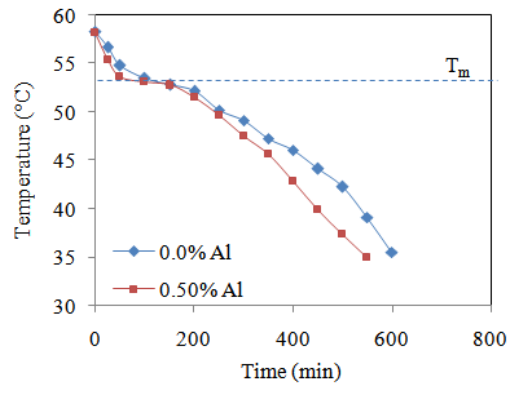

Fig. 8: Comparison of temperature inside the PCM (discharge process). For pure paraffin and composite at $\dot{\mathrm{m}}=0.03 \mathrm{~kg} \mathrm{sec}^{-1}$ and $\mathrm{T}_{\mathrm{i}}=35^{\circ} \mathrm{C}$

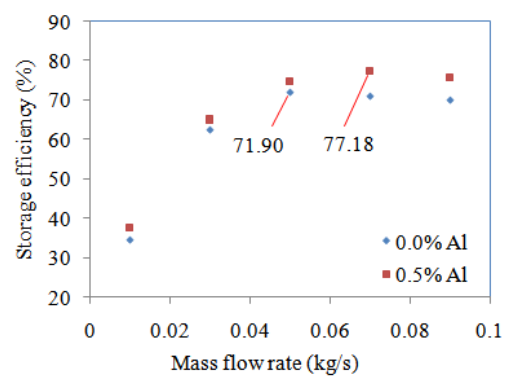

Fig. 9: Effect of mass flow rate on thermal storage efficiency for pure paraffin wax and the compound when $\mathrm{T}_{\mathrm{i}}=35^{\circ} \mathrm{C}$

\section{CONCLUSION}

In this study, an indoor testing system consisting of solar heater integrated with PCM unit has been fabricated and studied. The charging time decreased by $70 \%$ for composite than pure paraffin wax due to the high thermal conductivity of the aluminum powder. Thermal storage efficiency of the solar heater obtained at indoor condition reached the maximum magnitudes which were $71.9 \%$ and $77.18 \%$ at mass flow rates 0.05 and $0.07 \mathrm{~kg} \mathrm{sec}^{-1}$ for pure paraffin wax and the compound(paraffin wax with $0.5 \%$ mass aluminum powder)respectively. The capsules fabrication procedure can be used by manufacturers and researchers in laboratories.

\section{ACKNOWLEDGEMENT}

This study was supported by the Solar Energy Research Institute (SERI), University Kebangsaan Malaysia. The authors wish to thank (SERI) for their support.

\section{REFERENCES}

Alkilani, M.M., K. Sopian, S. Mat and M.A. Alghol, 2009. Output air temperature prediction in a solar air heater integrated with phase change material. Eur. J. Sci. Res., 27: 334-341.

Baehr, H.D. and K. Stephan, 2010. Wärme- und Stoffübertragung. 7th Edn., Springer, Berlin Heidelberg, ISBN: 3642055001, pp: 791.

Choudhury, C., P.M. Chauhan and H.P. Garg, 1995. Economic design of a rock bed storage device for storing solar thermal energy. Solar Ene., 55: 29-37. DOI: 10.1016/0038-092X(95)00023-K

Enibe, S.O., 2002. Performance of a natural circulation solar air heating system with phase change material energy storage. Renew. Ene., 27: 69-86. DOI: 10.1016/S0960-1481(01)00173-2

Enibe, S.O., 2003. Thermal analysis of a natural circulation solar air heater with phase change material energy storage. Renew. Ene., 28: 22692299. DOI: 10.1016/S0960-1481(03)00071-5

Fatah, H.E.S., 1995. Thermal performance of a simple design solar air heater with built-in thermal energy storage system. Renew. Ene., 6: 1033-1039. DOI: 10.1016/0960-1481(94)00085-6

Garg, H.P., A.R. Sukla, I. Madhuri, R.C. Agnihotri and S. Chakravertty, 1985. Development of a simple low-cost solar simulator for indoor collector testing. Applied Ene., 21: 43-54. DOI: 10.1016/0306-2619(85)90073-X

Lane, G.A., 1976. Encapsulation of heat of fusion storage materials. Proceedings of 2nd Southeastern Conference on Application of Solar Energy, Apr. 19-22, Baton Rouge, Louisiana, pp: 442-450.

Lane, G.A., 1980. Low temperature heat storage with phase change materials. Int. J. Ambient Ene., 1:155-168. DOI: 10.1080/01430750.1980.9675731

McAdams, W.H., 1954. Heat Transmission. 3rd Edn., McGraw-Hill, New York, pp: 532.

Mehling, H. and L.F. Cabeza, 2008. Heat and Cold Storage with PCM: An up to Date Introduction into Basics and Applications. 1st Edn., Springer, Berlin, New York, ISBN: 3540685561, pp: 308.

Solomon, A., 1981. Some approximations of use in predicting the behavior of a PCM cylinder array. Lett. Heat Mass Transfer, 8: 237-246. DOI: 10.1016/0094-4548(81)90018-7 